\title{
Addressing the worldwide hepatocellular carcinoma: epidemiology, prevention and management
}

\author{
Hrishikesh Samant ${ }^{1}$, Hosein Shokouh Amiri ${ }^{2}$, Gazi B. Zibari ${ }^{2}$ \\ ${ }^{1}$ Division of Gastroenterology and Hepatology, LSU Health Science Center, Shreveport, LA, USA; ${ }^{2}$ John C McDonald Transplant Center, Willis \\ Knighton Health System, Shreveport, LA, USA \\ Contributions: (I) Conception and design: H Samant; (II) Administrative support: None; (III) Provision of study materials or patients: GB Zibari; \\ (IV) Collection and assembly of data: H Samant; (V) Data analysis and interpretation: H Samant; (VI) Manuscript writing: All authors; (VII) Final \\ approval of manuscript: All authors. \\ Correspondence to: Hrishikesh Samant, MD. John C McDonald Transplant Center, 2751 Albert Bicknell Drive, Shreveport, LA 71103, USA. \\ Email: hsaman@1suhsc.edu.
}

\begin{abstract}
Hepatocellular carcinoma (HCC) is the sixth most common cancer in the world with rising incidence. Globally, there has been substantial variation in prevalence of risk factors for HCC over years, like control of viral hepatitis in developing countries but growing epidemic of fatty liver disease in developed world. Changing epidemiology of HCC is related to trends in these risk factors. HCC remains asymptomatic until it is very advanced which makes early detection by surveillance important in reducing HCC related mortality. Management of HCC. depends on stage of the tumor and severity of underlying liver disease. At present, resection and transplant are still the best curative options for small HCC, but recent advances in locoregional therapy and molecular targeted systemic therapy has changed the management for HCC at intermediate and advanced stages. This review is overview of global epidemiology, prevention, surveillance and emerging therapies for hepatocellular carcinoma.
\end{abstract}

Keywords: Hepatocellular carcinoma (HCC); liver transplant; resection; trans arterial chemoembolization (TACE)

Submitted Dec 21, 2019. Accepted for publication Jan 22, 2020.

doi: 10.21037/jgo.2020.02.08

View this article at: http://dx.doi.org/10.21037/jgo.2020.02.08

\section{Introduction}

The burden of liver cancer is increasing worldwide (1). World Health Organization estimates that more than 1 million people will die from liver cancer in 2030 (2). The observed variation in racial and geographic distribution of HCC is mainly related to specific risk factors. For example, Asia and Africa have high prevalence due to hepatitis $\mathrm{C}$ virus $(\mathrm{HCV})$ and hepatitis $\mathrm{B}$ virus (HBV) infection; while the incidence in the US and Western Europe has increased during past decade with Hepatitis C reaching maturity and non-alcoholic fatty liver rising as distinctive risk factor. As major predisposing conditions for HCC are well identified, high-risk groups can be followed with screening.

Hepatocellular carcinoma HCC is unique because its prognosis depends on both stage of the tumor and severity of the underlying liver disease. Curative options like liver transplantation (LT) and surgical resection are available only in early stages $(3,4)$. However recently there is significant advances in available locoregional treatments and systemic therapies for advanced HCC.

\section{Hepatocellular carcinoma worldwide (Figure 1)}

The high mortality ratio of liver cancer made it fourth leading cause of cancer death globally. A total of 841,000 (4.7\%) new HCCs are estimated to have occurred in 2018 in addition to $782,000(8.2 \%)$ HCC related deaths (5). The overall incidence of HCC is heterogeneous probably due to variation in prevalence of hepatitis virus and environmental factors. Approximately $80 \%$ of HCC cases occur in subSaharan Africa and Eastern Asia following the similar high 

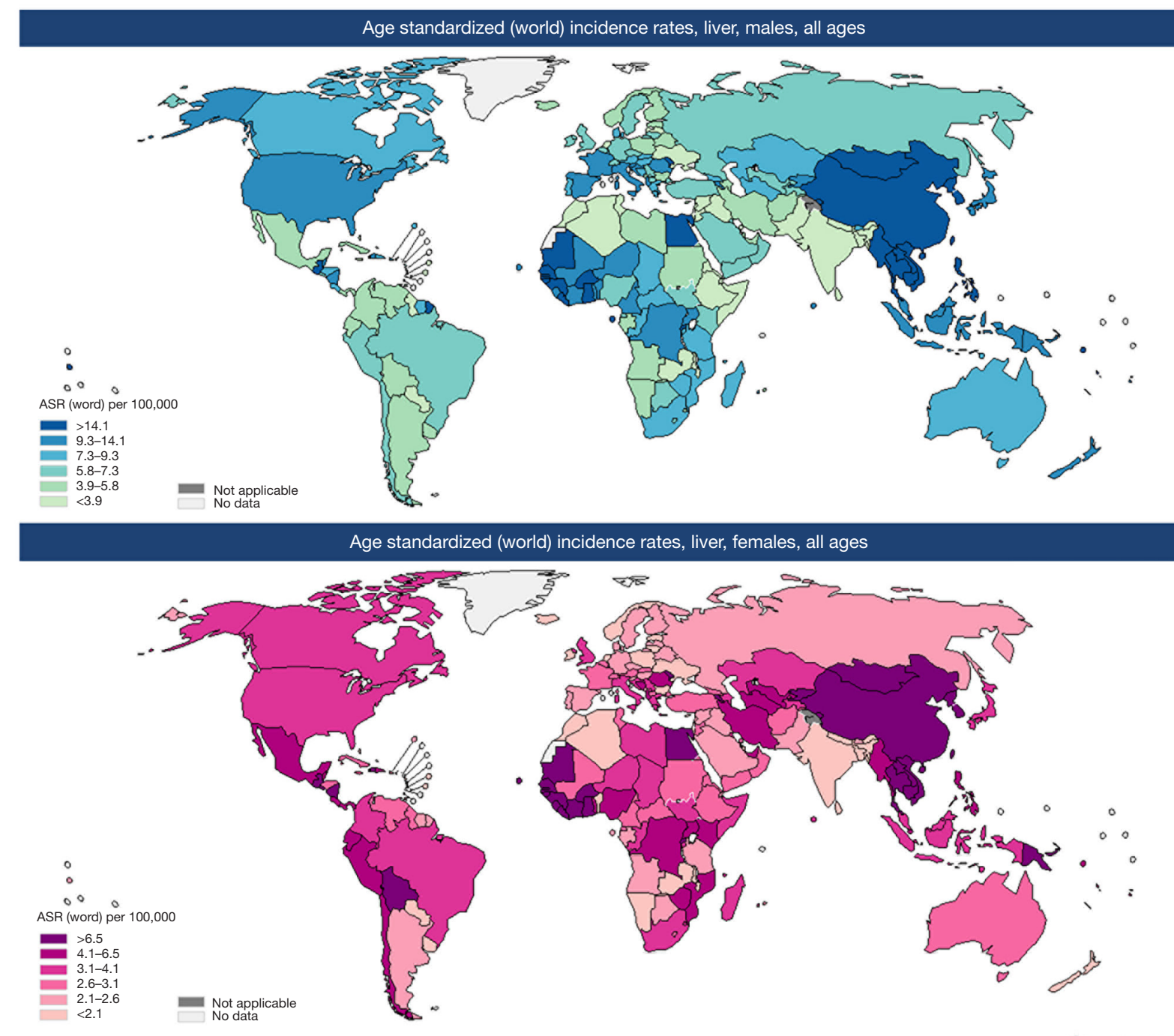
Data source: GLOBOCAN 2018
Graph production: IARC (http://gco.farc.fr/today.)
World Health Organization

\section{Age standardized (world) incidence rates, liver, by sex}

d) incidence rates, liver, females, all ages
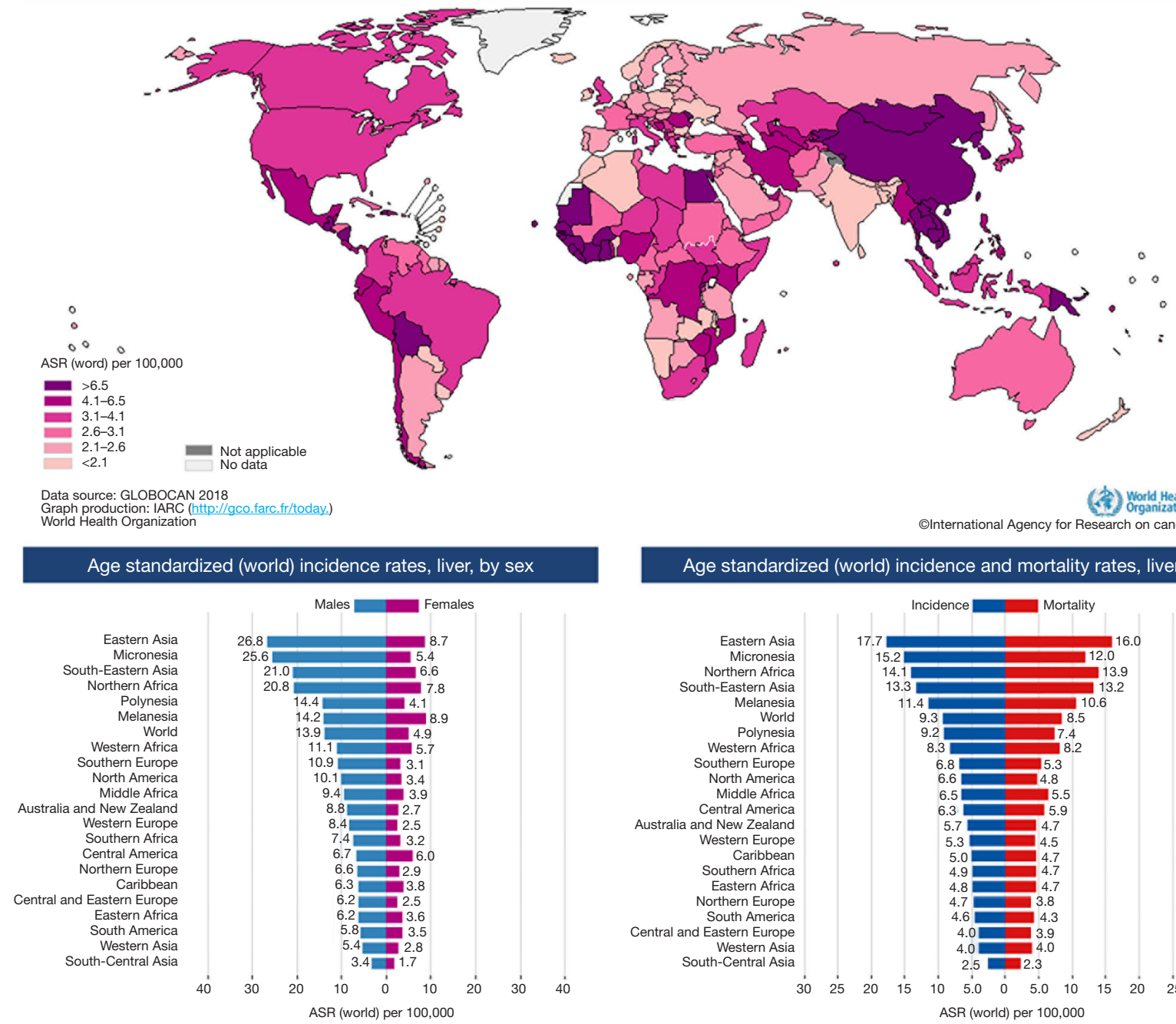

(d) World Heath

OInternational Agency for Research on cancer 2018

\section{Age standardized (world) incidence and mortality rates, liver}

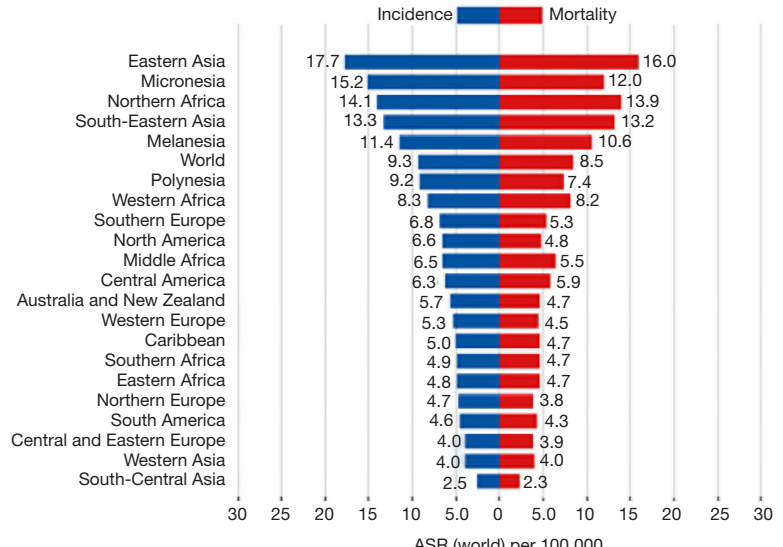

Figure 1 Estimated age-standardized rates of incident cases, both sexes, liver cancer, worldwide in 2018. 
prevalence pattern of chronic hepatitis B virus carriers in these regions. Thailand, Indonesia, Jamaica, Haiti, New Zealand, and Alaska fall under Intermediate-incidence areas; whereas Japan, North and South America, most of Europe, Australia, and Middle East are reported to be low-incidence regions (less than 3 cases reported per 100,000 populations per year) for HCC where hepatitis $\mathrm{C}$ is the major risk factor (6). Incidence in Japan has dropped drastically with significant reduction in their HCV population. Similarly, HCC incidence in China is on decline owing to increasing vaccination against hepatitis B (7). In all the parts of world, HCC occurs two to three times more often in males than in females with more disparity in high incidence regions.

In United states, incidence of HCC has tripled over the last four decades, possible from maturity of chronic hepatitis C patient pool. Burden of HCC is expected to reach 22 million cases in the next two decades (8). Interestingly, rising prevalence of obesity and associated fatty liver disease are believed now for this predicted increase in HCC patients (9). Population-based studies in the US have shown distribution of HCC differs amongst various racial and ethnic groups like Asians/Pacific Islanders (APIs) have higher rates of HCC compared with other Caucasians and Hispanics (10). In United States, reported average five-year survival for HCC is $14 \%$ and it is likely to be poorer in developing countries (11).

\section{Addressing the risk factors}

\section{Hepatitis B}

Hepatitis B virus infection is still the predominant risk factor for HCC, mainly in Asian countries, where more than half of the world's HCC population live (12). Apart from causing cirrhosis, Hepatitis B virus itself plays critical role in development of HCC (13). In vitro studies have shown that Hepatitis B virus can cause activation of oncogenes while integrating into host DNA (14). Chronic hepatitis B carriers without evidence of cirrhosis also can develop liver cancer (15). Incidence of HCC in patients with chronic $\mathrm{HBV}$ in East Asia is reported to be 0.2 per 100 person-years in chronic HBV carriers, and 3.7 per 100 person-years for those with compensated cirrhosis (16,17). Multiple host factors like male gender, older age, family history of HCC, use of alcohol or tobacco and virus-related factors like HBV genotype $\mathrm{C}$, pre-core $\mathrm{HBV}$ mutations and coinfection with $\mathrm{HCV}, \mathrm{HDV}$ or HIV increase the risk of HBV related
$\operatorname{HCC}(18,19)$.

Most important risk factor related to HCC development is $\mathrm{HBV}$ viral load and maintaining undetectable circulating $\mathrm{HBV}$ virus with oral antivirals has shown to reduce the incidence of development of HCC (20). Another strategy to reduce HBV related HCC incidence is vaccination against HBV infection (21). The best example of this is Taiwan where 30 years after the initiation of universal newborn vaccination, HBV carrier rates have fallen from $10-17 \%$ to $0.7-1.7 \%$ and rates of HCC have fallen by $80 \%(22,23)$. Still, there is a need to eradicate HBV infection and new research targeting the cell receptor, cccDNA of HBV etc., appears promising $(24,25)$.

\section{Hepatitis C}

Most of the HCC in developed countries is related to chronic HCV. HCV increases the risk of developing HCC almost 17 -fold. Cirrhosis is the major risk factor for HCC development. This risk is further increased in combination with alcohol abuse, coinfection with HBV, diabetes mellitus, older age, African American race and smoking. HCV infection remains asymptomatic most of the life, early detection by screening followed by treatment is crucial to reduce the incidence of $\mathrm{HCV}$ associated cirrhosis and subsequent risk of development of liver cancers.

Current CDC guidelines for screening in the general population include recommendation for individuals in the baby boomer birth cohort with highest HCV prevalence (people born between 1945 and 1965) and those at high risk of acquisition of $\mathrm{HCV}$ (history of intravenous drug use, blood transfusion or solid organ transplantation before 1992 and clotting factors before 1987, chronic hemodialysis, health care workers and children born of HCV-positive mothers) $(26,27)$. Risk-based HCV screening is reported to be inadequate and there is always need for better HCV screening strategies. Fortunately, development of all oral, highly effective, Directly Antiviral Agents (DAA) therapy against $\mathrm{HCV}$ has revolutionized the management of chronic HCV infection with 95-98\% success rate (28). Treatment of all patients with $\mathrm{HCV}$ is recommended, because progression to cirrhosis is associated with substantial risk of HCC development and/or costs for lifelong HCC surveillance (29). Also, recent study by Singal et al. have shown that treatment with DAAs is associated with increased survival amongst HCV related HCC population (30). 
Nonalcobolic fatty liver disease (NAFLD)

NAFLD is hepatic manifestoing of the metabolic syndrome -obesity, dyslipidemia and diabetes mellitus type 2 . $\mathrm{NASH}$ (non-alcoholic steatohepatitis) is more aggressive form of NAFLD with inflammation which can progress to cirrhosis with subsequent development of HCC (31) Global prevalence of NAFLD is reported around 25\%, with the highest rates in South America (31\%) and the Middle East (32\%), followed by Asia (27\%), the United States (24\%), and Europe (23\%) with lowest in Africa (32). Further, NASH is now becoming one of the most common etiologies for chronic liver disease worldwide (33). Risk of developing HCC from NASH-cirrhosis can range from $2.4 \%$ to $12.8 \%$ (34). Data of diabetes and HCC have shown relative risks of 2.0-2.5 independent of other risk factors (35-37). Similarly, a meta-analysis of metabolic syndrome and HCC reported a significant relative risk of $1.81(38,39)$.

Possible strategies to prevent HCC development in patients with NAFLD/NASH concentrate on lifestyle changes to prevent progression of liver fibrosis (31). Potential newer therapies for NASH are still in clinical trials with inconsistent results and we are still waiting for successful medications for NASH (40). At present, only diet and weight have shown best outcomes with improvement of liver enzymes and fibrosis $(41,42)$. Other medications hypothesize to reduce the risk of NASH related HCC are metformin and statins $(43,44)$. However, their antineoplastic effects still need more clinical evidence. Given the increasing prevalence NASH associated HCC; efforts should continue to better understand the implications and risks of NAFLD-NASH for HCC.

\section{Environmental toxins}

Evidence suggests that certain occupational and environmental factors also play role in development of HCC. Among those are exposure to aflatoxin, contamination of ground water by industrial waste like inorganic arsenic, workplace exposure to polycyclic aromatic hydrocarbons. Aflatoxin is predominantly produced by fungi which can contaminate food or water. Aflatoxin B1 is the most potent liver carcinogen (45). There is definite interaction between Aflatoxin B1 and HBV on HCC risk (46). The fraction of HCC cases attributable to aflatoxin exposure has been estimated to be 4.6-28.2\% (47). Porru $\mathrm{et} \mathrm{al}$. showed increased risk of HCC amongst workers chronically exposed to organic solvents like toluene and xylene (48). In epidemiological studies, groundwater contamination with inorganic arsenic has been reported with increased risk of HCC (49).

As we learn more about these environmental and occupational hazards, there will be additional opportunities to intervene and prevent HCC worldwide.

\section{Lifestyle factors}

It is well established alcohol intake with resulting cirrhosis has causal relationship with development of HCC (50). $\mathrm{HBV}$ and $\mathrm{HCV}$, in conjunction with alcohol, have synergistic effects on HCC risk (51-53). A metanalysis of alcohol and liver cancer estimated a $16 \%$ increased risk of liver cancer among consumers of 3 or more drinks per day and $22 \%$ increased risk among consumers of 6 more drinks per day (54). High alcohol consumption is thought to be contributing to the highest HCC prevalence in Mongolia (55).

Several epidemiological studies have revealed correlation between smoking and HCC. A meta-analysis on HCC and cigarette smoking, demonstrated the relative risk to be 1.51 for current smokers and 1.12 for former smokers (56).

This highlights impact of lifestyle factors on HCC prevalence.

\section{Surveillance}

American Association of the Study of Liver Diseases (AASLD) recommends enrollment in HCC surveillance program for all patients with cirrhosis regardless of etiology and high-risk chronic HBV carriers with ultrasound (US) with or without alpha-fetoprotein (AFP). High risk hepatitis $\mathrm{B}$ carriers are patients even without cirrhosis if they are Africans older than 20 years of age, Asians older than 40 years of age, or if they have a family history of HCC. US have the advantage of being noninvasive and inexpensive, but is operator dependent. Systemic reviews demonstrate US alone has sensitivity for HCC from 30-70\% $(57,58)$. Zhang et al. in their landmark randomized control study in chinses hepatitis B population $(n=18,816)$ reported $30 \%$ reduction in mortality with abdominal US and alphafetoprotein (AFP) every 6 months as screening strategy (59). Other observation studies support this surveillance strategy, showing a survival benefit $(60,61)$. At present, the concern is adherence to such surveillance program as data from Surveillance, Epidemiology, and End Results registry shows that less than $20 \%$ of patients who developed HCC had 


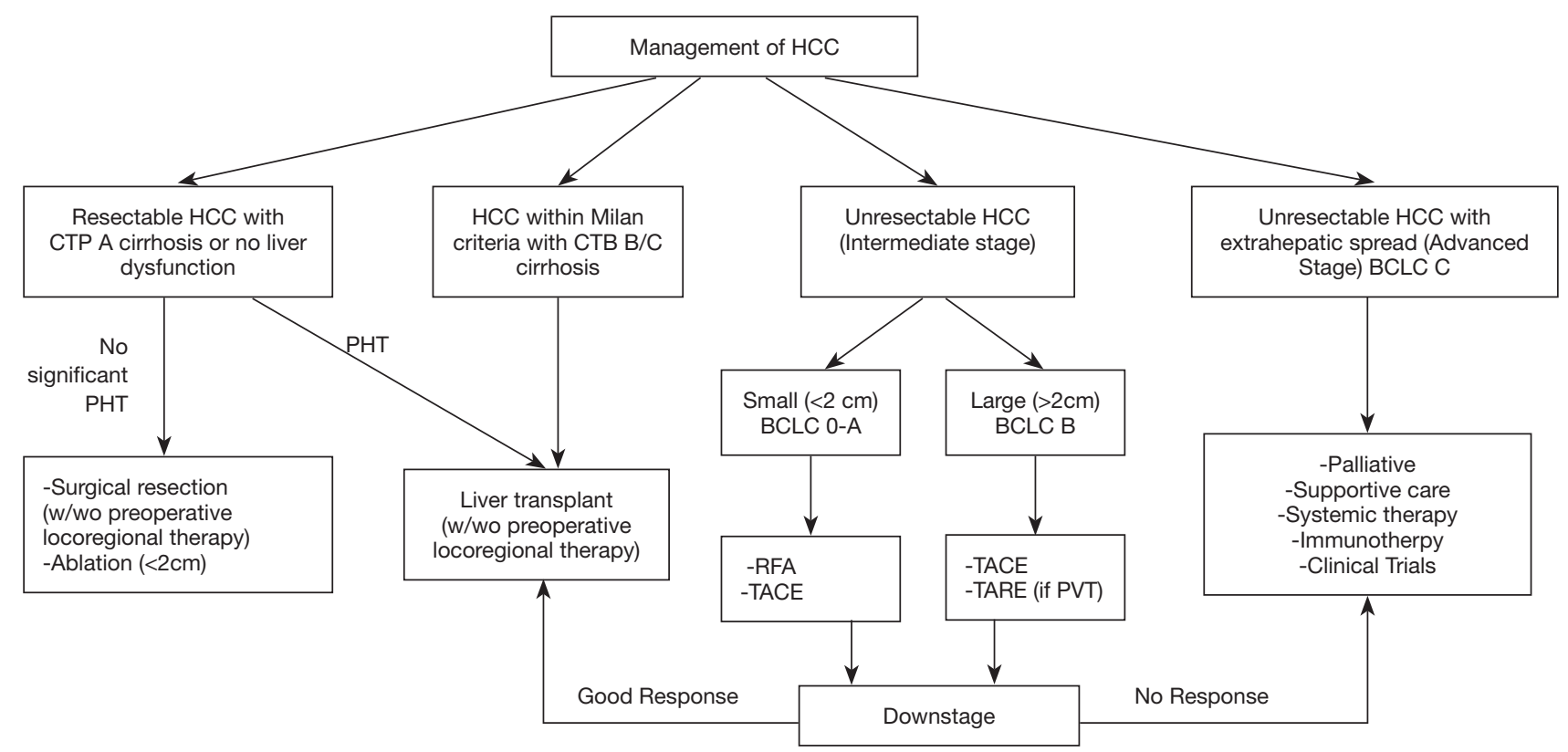

Figure 2 Management of HCC. HCC, hepatocellular carcinoma; BCLC, Barcelona Cancer classification; TACE, trans arterial chemoembolization; RFA, radiofrequency ablation.

received regular surveillance (62).

AFP alone should not be used as screening test due to low sensitivity $(63,64)$. However, complete exclusion of AFP as cost effective screening tool is controversial and European Association for the Study of the Liver (EASL) and AASLD did recommend the use of US with AFP for surveillance $(65,66)$.

\section{Diagnosis}

The diagnostic tests most commonly used for diagnosis of HCC are quadruple phase multidetector CT scan and dynamic contrast-enhanced MRI. On CT and MRI, typical HCC lesion shows intense arterial uptake followed by loss on enhancement or "washout" with demonstration of capsule during portal vein and/or equilibrium phase imaging $(67,68)$. Generally, AFP levels greater than $500 \mathrm{u} / \mathrm{L}$ in high risk patient suggest HCC but negative values do not rule out HCC. Other biomarkers like AFP-L3\% (ratio of AFP-L3 to total AFP) and Desgamma-carboxy prothrombin (DCP-abnormal form of prothrombin) have shown some promise but data is not sufficient for their routine use in diagnosis of HCC $(69,70)$.

For HCC $>1 \mathrm{~cm}$. if the single imaging characteristics are not typical, then a second sequential contrast enhanced imaging study is recommended. If both the imaging modalities are non-diagnostic then only biopsy is required. Sub-centimeter liver nodules being less likely malignant; needs follow up with imaging at interval of 3 to 6 months. Biopsy has its own falsies like high false negative rate, risk of bleeding and implantation metastasis (71). It is recommended to have expert pathology review and use of special immune-stains (glypican 3, heat shock protein 70, glutamine synthetase 91) on biopsies (72). AASLD guidelines recommend step wise approach for liver lesion with dynamic imaging to decreases the number of potential biopsies.

\section{Management (Figure 2)}

Hepatocellular carcinoma is lethal as most patients present with advanced disease with median survival around one year (73). In the past few years, advancement in locoregional treatments and emerging molecular targeted therapies, have improved short-term survival but resection and liver transplant are still the cornerstone of curative options for HCC (74). Selection of particular therapy depends on tumor size/location, underlying liver dysfunction, performance status, local expertise and availability. Multidisciplinary team evaluation, consisting of hepatologists, surgeons, intervention radiologist, oncologists and pathologists are recommended for the best decision planning of HCC. 


\section{Staging}

A number of staging systems are available for use in HCC, but the Barcelona Clinic Liver Cancer classification is the most widely preferred staging system. It is the only one that considers liver function, stage of tumor, and performance status of patients with HCC $(75,76)$.

\section{Surgical resection}

Carefully selected patients do benefit from surgical resection. The ideal candidate for resection is patient with single tumor confined to the liver without any vascular invasion and preserved liver function (Child's score A without significant portal hypertension), but this clinical situation is present is less than 5\% (77). Present data shows that post-resection 5 -year survival rate in selected candidate is as high as $70 \%$ (78). So far, reported perioperative mortality is approximately $2 \%(79,80)$. Most of these patients are at risk of post resection hepatic decompensation. Another concern is post resection tumor recurrence. There is no role of repeat resection for such tumor recurrences and only options left are salvage liver transplant or controlled by locoregional therapy or systemic chemotherapy (78).

\section{Liver transplant}

For HCC, not resectable due to underlying liver dysfunction, liver transplant (LT) remains the best option as it also cures underlying liver disease. Studies have shown that HCC, confined to liver with size within the Milan criteria (one lesion less than $5 \mathrm{~cm}$, or up to 3 lesions with each $3 \mathrm{~cm}$ or smaller), has post-transplant 5 -yr survival rate $>70 \%$ and a tumor recurrence rate $<15 \%(81-83)$.

In United States, UNOS (United Network for Organ Sharing) uses the MELD (Model for End-stage Liver Disease) score for prioritizing LT for patients with decompensated cirrhosis. Though MELD score is good predictor of mortality in cirrhosis, this score fails to predict mortality in the patient with HCC as underlying liver disease may not have decompensated (84). Hence, candidates with HCC within Milan criteria and AFP $<1,000 \mathrm{ng} / \mathrm{mL}$, receive "MELD exception" score of 28 after staying on transplant waitlist for 6 months to facilitate early transplant. A significant drawback of LT for HCC is the long waiting time to get donor organ and hence various locoregional therapies like radiofrequency ablation
(RFA), Trans arterial chemoembolization (TACE) or combinations are used to control the size of HCC and as bridge to transplant (85-88). UNOS has recently updated its transplant listing criteria for HCC beyond Milan criteria (89). Living donor liver transplant (LDLT) is also an option in high-volume well-equipped centers (90). Apart from tumor size and number, there is need for molecular markers of HCC to define tumor biology which can help in future liver transplant decision making (91).

\section{Locoregional therapies}

In last decade, use of several forms of locoregional therapies like RFA, cryoablation, TACE, etc. have increased role in management of HCC. Locoregional therapies have shown success in patients with very early stage HCC or downsizing size of tumor burden before resection or transplant.

\section{Radiofrequency ablation}

Radiofrequency ablation is most effective treatment to treat early stage HCC. In RFA, single or multiple needle electrodes are used to deliver electromagnetic waves to tumor causing thermal necrosis. RFA effect is size dependent. Studies show that RFA can achieve complete necrosis in $90 \%$ cases for HCC size $2 \mathrm{~cm}$ or smaller with local recurrence $<1 \%$ and $5 \mathrm{yr}$. survival ranging from $40-70 \%$ (92). Feng et al. in their study did not find any significant difference in survival between RFA and resection for single HCC up to $4 \mathrm{~cm}$ in diameter (93). However, recent meta-analysis of retrospective studies by $\mathrm{Li}$ et al. showed resection still has better long-term survival compared to RFA (94). However, there is no consensus as to whether RFA can replace surgical resection as first-line treatment for small tumors.

RFA is preferred for small HCC located away from major vessels and diaphragm to avoid potential damage to adjacent tissues and loss of efficacy due to large blood vessels causing the heat-sink phenomena. Further, RFA can be associated with pain, bleeding, hepatic abscess, hepatic decompensation and in such situations percutaneous ethanol injection (PEI) was used PEI was popular in past due to less adverse events and being cost effective. But PEI has major drawback of high local recurrence rate requiring multiple sessions. Three independent meta-analyses have shown that RFA achieves better local control and increased survival benefits in patients with small HCC compared to PEI (95-97). As a result, RFA has progressively replaced PEI 
as the preferred locoregional therapy over years. Recently major technical advances in RFA like cooled tip probe or expanded tip probe has promising outcome to become effective alternative to surgery in future (98).

\section{Microwave ablation and electroporation}

Microwave ablation is one more technique of local ablation, in which an implanted electrode induces an ultra-high speed alternating electric field into the tumor tissue (99). Irreversible electroporation is another technique in which delivered electrical pulses at microseconds rate causes tumor necrosis through irreversible cell membrane damage (100). The major advantages of these ablation techniques are safety to adjacent vasculature and surrounding structure (100).

\section{Cryoablation}

Cryoablation is a technique in which cryoprobe is used to apply alternating freeze-thaw cycles into the tumor directly. It has been most frequently applied in patients who are determined to have unresectable HCC intraoperatively. It may be preferred over RFA in peripheral lesion or when there is a high likelihood of collateral thermal damage.

\section{TACE}

TACE involves administration of chemotherapeutic and embolizing agents through hepatic artery selectively into the artery supplying the tumor to cause tumor necrosis. Most suitable patients are those with compensated underlying cirrhosis (bilirubin $<2$ ) without any vascular involvement or extrahepatic tumor spread. Studies comparing TACE with standard supportive care has reported significant survival benefit with TACE (101-103). In patients with Child-Pugh $\mathrm{B}$ or $\mathrm{C}$ class cirrhosis or HCC with portal vein thrombosis, TACE is contraindicated.

Currently, there are no consensus regarding number of sessions and treatment schedule (on demand with response or scheduled), choice of anticancer agents (e.g., mitomycin, cisplatin, and doxorubicin alone or in combination), embolizing agent (e.g., gelatin sponge particles or polyvinyl alcohol particles) or bland embolization $(104,105)$. Reported side effects of TACE are intrahepatic biloma, acute hepatic failure, liver infarction, abscess formation, chemotherapyrelated systemic toxicities and post embolization syndrome (106).

Doxorubicin-loaded drug eluting beads (DEB-TACE) is a new technique to increase predictable delivery of doxorubicin to HCC with reduced systemic side effects $(107,108)$. Apart from release of drug, these beads also cause embolization of tumor vascular supply causing subsequent ischemia and necrosis (109). TACE combination with other ablation techniques (RFA, microwave etc.) have shown to have better outcome compared either of the technique alone (110).

\section{Radioembolization}

Another treatment for intermediate stage HCC is selectively delivering radioactive isotope Yttrium 90 (Y-90) labeled microspheres to tumor via the hepatic artery (111). Yttrium 90 (Y-90) microspheres are smaller than DEB-TACE beads which allow them to be trapped in smaller tumor capillary bed to deliver Y-90 with beta radiation to tumor causing necrosis without surrounding liver tissue ischemia. Y-90 radioembolization has major advantage over TACE as can be used in patients with portal vein thrombosis (112). Y-90 toxicities have proven to be well tolerated $(113,114)$. Results of radioembolization are comparable to TACE $(115,116)$.

\section{Stereotactic body radiation therapy (SBRT)}

In SBRT multiple high-dose radiation fractions are delivered to a small, precisely defined tumor target with three-dimensional conformal radiation therapy techniques thus preventing radiation damage to surrounding normal liver tissue. However, it is available only in few centers and studies regarding its response are limited. Primarily it is seen as complementary treatment in localized HCC not amenable to ablative therapies due to vascular involvement with preserved underlying liver function.

\section{Molecular targeted Systemic therapy}

There is paradigm shift in the systemic therapy for advanced HCC with emergence of new molecularly targeted agents like multi-kinase inhibitors and immune check point inhibitors. Though these options are expensive, management of advanced HCC is now well beyond sorafenib.

\section{Sorafenib}

Sorafenib (Nexavar), orally active small molecule tyrosine kinase inhibitor (TKI) which inhibits Raf kinase and the vascular endothelial growth factor receptor (VEGFR) 
intracellular kinase pathway (117). The landmark SHARP trial reported a modest but statistically significant survival benefit for sorafenib in patients with advanced HCC which lead to its approval as a new first line treatment for advanced HCC in 2008 (118).

\section{Lenvatinib}

Lenvatinib is multi-kinase inhibitor targeting VEGFR, fibroblast growth factor receptors (FGFR) and plateletderived growth factor receptor (PDGFR). A randomized REFLECT study showed Lenvatinib was noninferior to sorafenib in patients with unresectable HCC (119). Lenvatinib was approved as first-line treatment of unresectable HCC in 2018.

\section{Nivolumab and pembrolizumab}

These are immune check-point inhibitor, targeting programmed cell death receptor (PD-1) and activating $\mathrm{T}$ cells against tumor, approved for treatment of HCC in patients previously treated with sorafenib. In Phase III CheckMate 459 trial in patients with advanced HCC, nivolumab was associated with a twofold higher objective response rate, but it failed to show significant benefit in overall survival (median 16.4 versus 14.7 months with sorafenib) (120). In phase II Keynote-224 trial in patients previously treated with sorafenib, pembrolizumab showed benefit (121).

\section{Regorafenib}

Regorafenib is newly approved second line therapy for patient with advanced HCC showing progression on sorafenib. Regorafenib is again oral multi kinase inhibitor active against VEGFR, stromal and oncogenic receptor tyrosine kinases, with more activity in angiogenic and tumor growth-promoting pathways.

\section{Cytotoxic conventional Systemic chemotherapy}

Role of cytotoxic chemotherapy is limited and its use is only in patients with advanced HCC who cannot afford these new expensive agents. Though, there is no recommended protocol for conventional chemotherapy, in general most centers use oral capecitabine or leucovorin-modulated fluorouracil regimen.

\section{Conclusions}

HCC is becoming worldwide public health problem due to rising prevalence and high mortality in both developing and developed world. To fight this important global health care challenge, controlling the risk factors and detecting the cancer early is important. The demography and risk factors for HCC are well known and vary with geography. Hepatitis $B$ vaccination and new effective anti $\mathrm{HCV}$ medications resulted in a decline in hepatitis $\mathrm{B}$ and elimination of $\mathrm{HCV}$, but the incidence of NASH and alcohol related HCC is growing. Surveillance of HCC is critical since the clinical outcome depends on the ability to identify this cancer in early stages. At present, resection and LT still remain the main curative therapy for early stage HCC and advances in the locoregional techniques for intermediate stage HCC continue to expand. There is recent resurgence in molecular targeted drugs in advanced HCC.

Multidisciplinary team approach is critical for HCC management as newer advances continue to change landscape of this disease.

\section{Acknowledgments}

Dr. Bhakti Samant for collecting and assembling the data. Funding: None.

\section{Footnote}

Provenance and Peer Review: This article was commissioned by the Guest Editors (John F. Gibbs and Quyen D. Chu) for the series "Global GI Malignancies" published in Fournal of Gastrointestinal Oncology. The article has undergone external peer review.

Conflicts of Interest: The authors have completed the ICMJE uniform disclosure form (available at http://dx.doi. org/10.21037/jgo.2020.02.08). The series "Global GI Malignancies" was commissioned by the editorial office without any funding or sponsorship. The authors have no other conflicts of interest to declare.

Ethical Statement: The authors are accountable for all aspects of the work in ensuring that questions related to the accuracy or integrity of any part of the work are appropriately investigated and resolved.

Open Access Statement: This is an Open Access article distributed in accordance with the Creative Commons Attribution-NonCommercial-NoDerivs 4.0 International License (CC BY-NC-ND 4.0), which permits the non- 
commercial replication and distribution of the article with the strict proviso that no changes or edits are made and the original work is properly cited (including links to both the formal publication through the relevant DOI and the license). See: https://creativecommons.org/licenses/by-nc-nd/4.0/.

\section{References}

1. Akinyemiju T, Abera S, Ahmed $M$ et al. The Burden of Primary Liver Cancer and Underlying Etiologies From 1990 to 2015 at the Global, Regional, and National Level: Results from the Global Burden of Disease Study 2015. JAMA Oncol 2017;3:1683.

2. World Health Organization. Projections of mortality and causes of death, 2016 to 2060. Accessed October 27, 2019. Available online: http://www.who.int/healthinfo/global_ burden_disease/projections/en/

3. Forner A, Llovet JM, Bruix J. Hepatocellular carcinoma. Lancet 2012;379:1245-55.

4. Marrero JA. Current Treatment Approaches in HCC. Clin Adv Hematol Oncol 2013;11 Suppl 5:15-8.

5. Bray F, Ferlay J, Soerjomataram I et al. Global Cancer Statistics 2018: GLOBOCAN Estimates of Incidence and Mortality Worldwide for 36 Cancers in 185 Countries. CA Cancer J Clin 2018;68:394-424.

6. Ferlay J, Ervik M, Lam F, et al. Estimating the global cancer incidence and mortality in 2018: GLOBOCAN sources and methods. Int J Cancer 2019;144:1941-53.

7. Kao JH, Chen DS. Changing disease burden of hepatocellular carcinoma in the Far East and Southeast Asia. Liver Int 2005;25:696-703.

8. Stewart BW, Wild CP. World cancer report 2014. Accessed July 27 2019. Available online: http://site.ebrary. com/id/11014806

9. El-Serag HB, Mason AC. Risk factors for the rising rates of primary liver cancer in the United States. Arch Intern Med 2000;160:3227-30.

10. Centers for Disease Control and Prevention (CDC). Hepatocellular carcinoma - United States, 2001-2006. MMWR Morb Mortal Wkly Rep 2010;59:517.

11. El-Serag HB. Hepatocellular Carcinoma. N Engl J Med 2011;365:1118-27.

12. Parkin DM. The global health burden of infectionassociated cancers in the year 2002. Int J Cancer 2006;118:3030-44.

13. But DY, Lai CL, Yuen MF. Natural history of hepatitisrelated hepatocellular carcinoma. World J Gastroenterol 2008;14:1652-6.
14. Feitelson MA. Hepatitis B virus in hepato-carcinogenesis. J Cell Physiol 1999;181:188-202.

15. Chen JD, Yang HI, Iloeje UH, et al. Carriers of inactive hepatitis B virus are still at risk for hepatocellular carcinoma and liver-related death. Gastroenterology 2010;138:1747-54.

16. Ulcickas Yood M, Quesenberry CP Jr, Guo D, et al. Incidence of hepatocellular carcinoma among individuals with hepatitis B virus infection identified using an automated data algorithm. J Viral Hepat 2008;15:28-36.

17. Fattovich G, Stroffolini T, Zagni I, et al. Hepatocellular carcinoma in cirrhosis: Incidence and risk factors. Gastroenterology 2004;127:S35-50.

18. Yang HI, Sherman M, Su J, et al. Nomograms for risk of hepatocellular carcinoma in patients with chronic hepatitis B virus infection. J Clin Oncol 2010;28:2437-44.

19. Sumi H, Yokosuka O, Seki N, et al. Influence of hepatitis $\mathrm{B}$ virus genotypes on the progression of chronic type $\mathrm{B}$ liver disease. Hepatology 2003;37:19-26.

20. Chen G, Lin W, Shen F et al. Past HBV viral load as predictor of mortality and morbidity from HCC and chronic liver disease in a prospective study. Am J Gastroenterol 2006;101:1797-803.

21. Goldstein ST, Zhou F, Hadler SC et al. A mathematical model to estimate global hepatitis B disease burden and vaccination impact. Int J Epidemiol 2005;34:1329-39.

22. Chang MH, You SL, Chen CJ, et al. Decreased incidence of hepatocellular carcinoma in hepatitis B vaccines: a 20-year follow-up study. J Natl Cancer Inst 2009;101:1348-55.

23. Chiang CJ, Yang YW, You SL et al. Thirty-year outcomes of the national hepatitis B immunization program in Taiwan. JAMA 2013;310:974-6.

24. Yan H, Peng B, Liu Y, et al. Viral entry of hepatitis $\mathrm{B}$ and $\mathrm{D}$ viruses and bile salts transportation share common molecular determinants on sodium taurocholate cotransporting polypeptide. J Virol 2014;88:3273-84.

25. Ding S, Robek MD. Cytidine deamination and cccDNA degradation: A new approach for curing HBV? Hepatology 2014;60:2118-21.

26. Denniston MM, Jiles RB, Drobeniuc J, et al. Chronic hepatitis $\mathrm{C}$ virus infection in the United States, National Health and Nutrition Examination Survey 2003 to 2010. Ann Intern Med 2014;160:293-300.

27. Smith BD, Morgan RL, Becketi GA, et al. Centers for Disease Control and Prevention. Recommendations for the identification of chronic hepatitis $\mathrm{C}$ virus infection among persons born during 1945-1965. MMWR Recomm 
Rep 2012;61:1-32.

28. AASLD-IDSA. When and in Whom to Initiate HCV Therapy. Accessed July 27, 2019. Available online: http:// www.hcvguidelines.org/evaluate/when-whom

29. Kanwal F, Kramer J, Asch SM, et al. Risk of hepatocellular cancer in HCV patients treated with direct-acting antiviral agents. Gastroenterology 2017;153:996-1005.e1.

30. Singal AG, Rich NE, Mehta N, et al. Direct-Acting Antiviral Therapy for Hepatitis C Virus Infection Is Associated With Increased Survival in Patients With a History of Hepatocellular Carcinoma. Gastroenterology 2019;157:1253-63.e2.

31. Degasperi E, Colombo M: Distinctive features of hepatocellular carcinoma in non- alcoholic fatty liver disease. Lancet Gastroenterol Hepatol 2016;1:156-64.

32. Younossi Z, Anstee QM, Marieti M, et al. Global burden of NAFLD and NASH: trends, predictions, risk factors and prevention. Nat Rev Gastroenterol Hepatol 2018;15:11-20.

33. Argyrou C, Moris D, Vernadakis S. Hepatocellular carcinoma development in non-alcoholic fatty liver disease and non-alcoholic steatohepatitis. Is it going to be the "Plague" of the 21st century? A literature review focusing on pathogenesis, prevention and treatment. J BUON 2017;22:6-20.

34. Khan FZ, Perumpail RB, Wong RJ, et al. Advances in hepatocellular carcinoma: nonalcoholic steatohepatitisrelated hepatocellular carcinoma. World J Hepatol 2015;7:2155-61.

35. Chen J, Han Y, Xu C, et al. Effect of type 2 diabetes mellitus on the risk for hepatocellular carcinoma in chronic liver diseases: a meta-analysis of cohort studies. Eur J Cancer Prev 2015;24:89-99.

36. El-Serag HB, Richardson PA, Everhart JE. The role of diabetes in hepatocellular carcinoma: a case-control study among United States Veterans. Am J Gastroenterol 2001;96:2462-7.

37. Wang C, Wang X, Gong G, et al. Increased risk of hepatocellular carcinoma in patients with diabetes mellitus: a systematic review and meta-analysis of cohort studies. Int J Cancer 2012;130:1639-48.

38. Larsson SC, Wolk A. Overweight, obesity and risk of liver cancer: a meta-analysis of cohort studies. Br J Cancer 2007;97:1005-8.

39. Jinjuvadia R, Patel S, Liangpunsakul S. The association between metabolic syndrome and hepatocellular carcinoma: systemic review and meta-analysis. J Clin Gastroenterol 2014;48:172-7.
40. Neuschwander-Tetri BA, Loomba R, Sanyal AJ, et al;NASH Clinical Research Network. Farnesoid X nuclear receptor ligand obetocholic acid for noncirrhotic, non-alcoholic steatohepatitis (FLINT): a multicenter, randomized, placebo-controlled trial. Lancet 2015;385:956-65.

41. European Association for the Study of the Liver (EASL) European Association for the Study of Diabetes (EASD) European Association for the Study of Obesity (EASO). EASL-EASD-EASO Clinical Practice Guidelines for the management of non-alcoholic fatty liver disease. J Hepatol 2016;64:1388-402.

42. Promrat K, Kleiner DE, Niemeier HM, et al. Randomized controlled trial testing the effects of weight loss on nonalcoholic steatohepatitis. Hepatology 2010;51:121-9.

43. Zhang ZJ, Zheng ZJ, Shi R, et al. Metformin for liver cancer prevention in patients with type 2 diabetes: a systematic review and meta -analysis. J Clin Endocrinol Metab 2012;97:2347-53.

44. Singh S, Singh PP, Singh AG, et al. Statins are associated with a reduced risk of hepatocellular cancer: a systematic review and meta-analysis. Gastroenterology 2013;144:323-32.

45. Madden CR, Finegold MJ, Slagle BL. Altered DNA Mutation Spectrum in Aflatoxin B1-Treated Transgenic Mice That Express the Hepatitis B Virus X Protein. J Virol 2002;76:11770-4.

46. Wu HC, Wang Q, Yang HI, et al. Aflatoxin B1 exposure, hepatitis B virus infection, and hepatocellular carcinoma in Taiwan. Cancer Epidemiol Biomarkers Prev 2009;18:846-53.

47. Liu Y, Wu F. Global burden of aflatoxin-induced hepatocellular carcinoma: a risk assessment. Environ Health Perspect 2010;118:818.

48. Porru S, Placidi D, Carta A, et al. Prevention of injuries at work: the role of the occupational physician. Int Arch Occup Environ Health 2006;79:177-92.

49. Chen Y, Ahsan H. Cancer Burden from Arsenic in Drinking Water in Bangladesh. Am J Public Health 2004;94:741-4.

50. Donato F. Alcohol and Hepatocellular Carcinoma: The Effect of Lifetime Intake and Hepatitis Virus Infections in Men and Women. Am J Epidemiol 2002;155:323-31.

51. Donato F, Tagger A, Gelatti U, et al. Alcohol and hepatocellular carcinoma: the effect of lifetime intake and hepatitis virus infections in men and women. Am J Epidemiol 2002;155:323-31.

52. Yuan JM, Govindarajan S, Arakawa K, et al. Synergism 
of alcohol, diabetes, and viral hepatitis on the risk of hepatocellular carcinoma in blacks and whites in the U.S. Cancer 2004;101:1009-17.

53. Kuper H, Tzonou A, Kaklamani E, et al. Tobacco smoking, alcohol consumption and their interaction in the causation of hepatocellular carcinoma. Int J Cancer 2000;85:498-502.

54. Turati F, Galeone C, Rota M, et al. Alcohol and liver cancer: a systematic review and meta- analysis of prospective studies. Ann Oncol 2014;25:1526-35.

55. Alcorn T. Mongolia's struggle with liver cancer. Lancet 2011;377:1139-40.

56. Lee YCA, Cohet C, Yang YC, et al. Meta-analysis of epidemiologic studies on cigarette smoking and liver cancer. Int J Epidemiol 2009;38:1497-511.

57. Outwater EK. Imaging of the liver for hepatocellular carcinoma. Cancer Control 2010;17:72-82.

58. Colli A, Fraquelli M, Casazza G, et al. Accuracy of ultrasonography, spiral CT, magnetic resonance, and alpha-fetoprotein in diagnosing hepatocellular carcinoma: a systematic review. Am J Gastroenterol 2006;101:513-23.

59. Zhang BH, Yang BH, Tang ZY. Randomized controlled trial of screening for hepatocellular carcinoma. J Cancer Res Clin Oncol 2004;130:417-22.

60. Trevisani F, De NS, Rapaccini G, et al. Semiannual and annual surveillance of cirrhotic patients for hepatocellular carcinoma: effects on cancer stage and patient survival (Italian experience). Am J Gastroenterol 2002;97:734-44.

61. Bolondi L, Sofia S, Siringo S, et al. Surveillance program of cirrhotic patients for early diagnosis and treatment of hepatocellular carcinoma: a cost effectiveness analysis. Gut 2001;48:251-9.

62. Davila JA, Morgan RO, Richardson PA, et al. Use of surveillance for hepatocellular carcinoma among patients with cirrhosis in the United States. Hepatology 2010;52:132-41.

63. Gupta S, Bent S, Kohlwes J. Test characteristics of alphafetoprotein for detecting hepatocellular carcinoma in patients with hepatitis C. A systematic review and critical analysis. Ann Intern Med 2003;139:46-50.

64. Sherman M. Serological surveillance for hepatocellular carcinoma: time to quit. J Hepatol 2010;52:614-5.

65. Bruix J, Sherman M, Llovet JM, et al. EASL Panel of Experts on HCC. Clinical management of hepatocellular carcinoma. Conclusions of the Barcelona-2000 EASL conference. J Hepatol 2001;35:421-30.

66. Marrero JA, El-Serag HB. Alpha-fetoprotein should be included in the hepatocellular carcinoma surveillance guidelines of the American Association for the Study of Liver Diseases. Hepatology 2011;53:1060-1.

67. Forner A, Vilana R, Ayuso C, et al. Diagnosis of hepatic nodules $20 \mathrm{~mm}$ or smaller in cirrhosis: prospective validation of the noninvasive diagnostic criteria for hepatocellular carcinoma. Hepatology 2008;47:97-104.

68. Sangiovanni A, Manini MA, Iavarone M, et al. The diagnostic and economic impact of contrast imaging techniques in the diagnosis of small hepatocellular carcinoma in cirrhosis. Gut 2010;59:638-44.

69. Marrero JA, Feng Z, Wang Y, et al. Alpha-fetoprotein, des-gamma carboxypro-thrombin, and lectin-bound alpha-fetoprotein in early hepatocellular carcinoma. Gastroenterology 2009;137:110-8.

70. Volk ML, Hernandez JC, Su GL, et al. Risk factors for hepatocellular carcinoma may impair the performance of biomarkers: a comparison of AFP, DCP, and AFP-L3. Cancer Biomark 2007;3:79-87.

71. Silva MA, Hegab B, Hyde C, et al. Needle track seeding following biopsy of liver lesions in the diagnosis of hepatocellular cancer: a systematic review and metaanalysis. Gut 2008;57:1592-6.

72. International Consensus Group for Hepatocellular Neoplasia. Pathologic diagnosis of early hepatocellular carcinoma: a report of the international consensus group for hepatocellular neoplasia. Hepatology 2009;49:658-64.

73. Nordenstedt H, White DL, El-Serag HB. The changing pattern of epidemiology in hepatocellular carcinoma. Dig Liver Dis 2010;42:S206-14.

74. Motola-Kuba D, Zamora-Valdés D, Uribe M, et al. Hepatocellular carcinoma. An overview. Ann Hepatol 2006;5:16-24.

75. Bruix J, Sherman M;American Association for the Study of Liver Diseases. Management of hepatocellular carcinoma: an update. Hepatology 2011;53:1020-2.

76. Arslanoglu A, Seyal AR, Sodagari F, et al. Current guidelines for the diagnosis and management of hepatocellular carcinoma: a comparative review. AJR Am J Roentgenol 2016;207:W88-98.

77. Wong R, Frenette C. Updates in the management of hepatocellular carcinoma. Gastroenterol Hepatol (N Y) 2011;7:16-24.

78. Allemann P, Demartines N, Bouzourene H, et al. Longterm outcome after liver resection for hepatocellular carcinoma larger than $10 \mathrm{~cm}$. World J Surg 2013;37:452-8.

79. Poon RT, Fan ST, Lo CM, et al. Long-term survival and pattern of recurrence after resection of small hepatocellular carcinoma in patients with preserved liver function: 
implications for a strategy of salvage transplantation. Ann Surg 2002;235:373-82.

80. Zhu AX. Systemic therapy of advanced hepatocellular carcinoma: how hopeful should we be? Oncologist 2006;11:790-800.

81. Mazzaferro V, Regalia E, Doci R, et al. Liver transplantation for the treatment of small hepatocellular carcinomas in patients with cirrhosis. $\mathrm{N}$ Engl J Med 1996;334:693-9.

82. Mazzaferro V. Results of liver transplantation: with or without Milan criteria? Liver Transpl 2007;13:S44-7.

83. Mazzaferro V, Bhoori S, Sposito C, et al. Milan criteria in liver transplantation for hepatocellular carcinoma: an evidence-based analysis of 15 years of experience. Liver Transpl 2011;17 Suppl 2:S44-57.

84. Taniguchi M. Liver transplantation in the MELD era analysis of the OPTN/UNOS registry. Clin Transpl 2012;41-65.

85. Cucchetti A, Cescon M, Bigonzi E et al. Priority of candidates with hepatocellular carcinoma awaiting liver transplantation can be reduced after successful bridge therapy. Liver Transpl 2011;17:1344-54.

86. Yao FY, Kerlan RK, Hirose R, et al. Excellent outcome following down-staging of hepatocellular carcinoma prior to liver transplantation: an intention-to-treat analysis. Hepatology 2008;48:819-27.

87. Clavien PA, Lesurtel M, Bossuyt PM, et al. Recommendations for liver transplantation for hepatocellular carcinoma: an international consensus conference report. Lancet Oncol 2012;13:e11-22.

88. Washburn K, Halff G. Hepatocellular carcinoma and liver transplantation. Curr Opin Organ Transplant 2011;16:297-300.

89. US Department of Health and Human Services Health Resources and Services Administration Organ Procurement and Transplantation Network. Accessed July 27, 2019. Available online: http://optn.transplant.hrsa.gov/ policiesAndBylaws/policies.asp

90. Mancuso A. Management of hepatocellular carcinoma: enlightening the gray zones. World J Hepatol 2013;5:302-10.

91. Schwartz M, Dvorchik I, Llovet JM et al. Liver transplantation for hepatocellular carcinoma: extension of indications based on molecular markers. J Hepatol 2008;49:581-8.

92. Livraghi T, Meloni F, Di Stasi M, et al. Sustained complete response and complications rates after radiofrequency ablation of very early hepatocellular carcinoma in cirrhosis:
Is resection still the treatment of choice? Hepatology 2008;47:82-9.

93. Feng K, Yan J, Li X, et al. A randomized controlled trial of radiofrequency ablation and surgical resection in the treatment of small hepatocellular carcinoma. J Hepatol 2012;57:794-802.

94. Li X, Wu Y, Chen D, et al. Laparoscopic hepatectomy versus radiofrequency ablation for hepatocellular carcinoma: a systematic review and meta-analysis. Cancer Manag Res 2019;11:5711-24.

95. Orlando A, Leandro G, Olivo M, et al. Radiofrequency thermal ablation vs. percutaneous ethanol injection for small hepatocellular carcinoma in cirrhosis: meta-analysis of randomized controlled trials. Am J Gastroenterol 2009;104:514-24.

96. Cho YK, Kim JK, Kim MY, et al. Systematic review of randomized trials for hepatocellular carcinoma treated with percutaneous ablation therapies. Hepatology 2009;49:453-9.

97. Shen A, Zhang H, Tang C, et al. Systematic review of radiofrequency ablation versus percutaneous ethanol injection for small hepatocellular carcinoma up to $3 \mathrm{~cm}$. J Gastroenterol Hepatol 2013;28:793-800.

98. Cucchetti A, Piscaglia F, Cescon M, et al. Costeffectiveness of hepatic resec- tion versus percutaneous radiofrequency ablation for early hepatocellular carcinoma. J Hepatol 2013;59:300-7.

99. Liang P, Wang Y. Microwave ablation of hepatocellular carcinoma. Oncology 2007;72 Suppl 1:124-31.

100. Davalos RV, Mir IL, Rubinsky B. Tissue ablation with irreversible electroporation. Ann Biomed Eng 2005;33:223-31.

101.Llovet JM, Bruix J. Systematic review of randomized trials for unresectable hepatocellular carcinoma: Chemoembolization improves survival. Hepatology 2003;37:429-42.

102.Llovet JM, Real MI, Montana X, et al. Arterial embolization or chemoembolization versus symptomatic treatment in patients with unresectable hepatocellular carcinoma: a randomized controlled trial. Lancet 2002;359:1734-9.

103.Lo CM, Ngan H, Tso WK, et al. Randomized controlled trial of trans-arterial lipiodol chemoembolization for unresectable hepatocellular carcinoma. Hepatology 2002;35:1164-71.

104.Lencioni R. Loco-regional treatment of hepatocellular carcinoma. Hepatology 2010;52:762-73.

105. Raoul JL, Heresbach D, Bretagne JF, et al. 
Chemoembolization of hepatocellular carcinomas. A study of the biodistribution and pharmacokinetics of doxorubicin. Cancer 1992;70:585-90.

106. Sakamoto I, Aso N, Nagaoki K, et al. Complications associated with transcatheter arterial embolization for hepatic tumors. Radiographics 1998;18:605-19.

107.Lammer J, Malagari K, Vogl T, et al. PRECISION $\mathrm{V}$ Investigators. Prospective randomized study of doxorubicin-eluting-bead embolization in the treatment of hepatocellular carcinoma: results of the PRECISION V study. Cardiovasc Intervent Radiol 2010;33:41-52.

108. Varela M, Real MI, Burrel M, et al. Chemoembolization of hepatocellular carcinoma with drug eluting beads: efficacy and doxorubicin pharmacokinetics. J Hepatol 2007;46:474-81.

109.Poon RT, Tso WK, Pang RW, et al. A phase I/II trial of chemoembolization for hepatocellular carcinoma using a novel intraarterial drug-eluting bead. Clin Gastroenterol Hepatol 2007;5:1100-8.

110. Katsanos K, Kitrou P, Spiliopoulos S, et al. Comparative effectiveness of different transarterial embolization therapies alone or in combination with local ablative or adjuvant systemic treatments for unresectable hepatocellular carcinoma: A network metaanalysis of randomized controlled trials. PLoS One 2017;12:e0184597.

111. Kennedy A, Coldwell D, Sangro B, et al. Radioembolization for the treatment of liver tumors general principles. Am J Clin Oncol 2012;35:91-9.

112.Kulik LM, Carr BI, Mulcahy MF, et al. Safety and efficacy of $90 \mathrm{Y}$ radiotherapy for hepatocellular carcinoma with and without portal vein thrombosis. Hepatology 2008;47:71-81.

113. Salem R, Lewandowski RJ, Mulcahy MF, et al. Radioembolization for hepatocellular carcinoma using Yttrium-90 microspheres: a comprehensive report of longterm outcomes. Gastroenterology 2010;138:52-64.

Cite this article as: Samant H, Amiri HS, Zibari GB. Addressing the worldwide hepatocellular carcinoma: epidemiology, prevention and management. J Gastrointest Oncol 2021;12(Suppl 2):S361-S373. doi: 10.21037/ jgo.2020.02.08
114. Salem R, Lewandowski RJ, Atassi B, et al. Treatment of unresectable hepatocellular carcinoma with use of $90 \mathrm{Y}$ microspheres (TheraSphere): safety, tumor response, and survival. J Vasc Interv Radiol 2005;16:1627-39.

115. Kooby DA, Egnatashvili V, Srinivasan S, et al. Comparison of yttrium-90 radioembolization and transcatheter arterial chemoembolization for the treatment of unresectable hepatocellular carcinoma. J Vasc Interv Radiol 2010;21:224-30.

116. Salem R, Lewandowski RJ, Kulik L, et al. Radioembolization results in longer time-to-progression and reduced toxicity compared with chemoembolization in patients with hepatocellular carcinoma. Gastroenterology 2011;140:497-507.e2.

117.Liu L, Cao Y, Chen C, et al. Sorafenib blocks the RAF/ MEK/ERK pathway, inhibits tumor angiogenesis, and induces tumor cell apoptosis in hepatocellular carcinoma model PLC/PRF/5. Cancer Res 2006;66:11851.

118. Llovet JM, Ricci S, Mazzaferro V, et al. Sorafenib in advanced hepatocellular carcinoma. N Engl J Med 2008;359:378.

119. Kudo M, Finn RS, Qin S, et al. Lenvatinib versus sorafenib in first-line treatment of patients with unresectable hepatocellular carcinoma: a randomized phase 3 noninferiority trial. Lancet 2018;391:1163.

120. Sangro B, Park JW, Cruz CMD. A randomized, multicenter, phase 3 study of nivolumab vs sorafenib as first-line treatment in patients (pts) with advanced hepatocellular carcinoma (HCC): CheckMate-459. J Clin Oncol 2017. doi: 10.1200/JCO.2016.34.15_suppl. TPS4147

121.Zhu AX, Finn RS, Edeline J, et al. Pembrolizumab in patients with advanced hepatocellular carcinoma previously treated with sorafenib (KEYNOTE-224): a non-randomised, open-label phase 2 trial. Lancet Oncol 2018;19:940-52. 